\title{
Avaliação da exposição ao chumbo sobre o padrão de metilação de regiões promotoras de genes relacionados ao metabolismo do metal, em trabalhadores de fábricas de baterias automotivas.
}

\author{
Dissertação de Mestrado apresentada ao \\ Programa de Pós-Graduação em Toxicologia da \\ Faculdade de Ciências Farmacêuticas de Ribeirão \\ Preto/USP para obtenção do título de Mestre em \\ Ciências \\ Área de Concentração: Toxicologia \\ Orientador: Prof. Dr. Gustavo Rafael Mazzaron \\ Barcelos
}

Versão corrigida da Dissertação de Mestrado apresentada ao Programa de Pós-Graduação em Toxicologia no dia 28/11/2017. A versão original encontra-se disponível na Faculdade de Ciências Farmacêuticas de Ribeirão Preto/USP

\section{Ribeirão Preto}




\section{RESUMO}

\section{DEVÓZ, P.P. Avaliação da exposição ao chumbo sobre o padrão de metilação de regiões} promotoras de genes relacionados ao metabolismo do metal, em trabalhadores de fábricas

de baterias automotivas. 2017. 53f. Dissertação (Mestrado). Faculdade de Ciências

Farmacêuticas de Ribeirão Preto - Universidade de São Paulo, Ribeirão Preto, 2017.

O chumbo $(\mathrm{Pb})$ é um metal tóxico que se acumula no organismo e provoca diversos efeitos, afetando vários sistemas, tais como renal, gastrointestinal, reprodutor, endócrino, hepático e hematopoiético. No que se refere a estudos epigenéticos, quando comparados a outros metais, o $\mathrm{Pb}$ é, até o momento, o menos estudado e, portanto, muito pouco se sabe a respeito dos efeitos epigenéticos sobre a absorção, distribuição, metabolismo e excreção (ADME) do Pb e, consequentemente, sobre a toxicidade induzida pela exposição ao $\mathrm{Pb}$. Assim, o objetivo do presente estudo consiste em avaliar o padrão de metilação de regiões promotoras dos genes GCLC e MT2A, quantificar a porcentagem de metilação global além das dosagens de parâmetros hepáticos e renais e associá-los à exposição ao $\mathrm{Pb}$. De acordo com os guidelines STROBE e STREGA, 100 trabalhadores do sexo masculino com idades entre 18 e 67 anos participaram do trabalho. Cerca de 6,0 mL de sangue e 5,0 mL de soro foram coletados após a assinatura do Termo de Consentimento Livre e Esclarecido (TCLE). As concentrações de $\mathrm{Pb}$ no sangue ( $\mathrm{Pb}-\mathrm{s})$ e no plasma $(\mathrm{Pb}-\mathrm{p})$ foram determinadas por espectrometria de massas com plasma indutivamente acoplado (ICP-MS); o DNA genômico foi extraído do sangue total e quantificado por kits específicos. As amostras de DNA foram tratadas com bissulfito de sódio e a quantificação da porcentagem de metilação global do DNA dos indivíduos expostos ao metal foi determinada pelo método de Elisa indireto e o sequenciamento das amostras para avaliar o padrão de metilação de regiões promotoras dos genes GCLC (Subunidade Catalítica de GlutamatoCisteína Ligase) e MT2A (Metalotioneína 2A), pela técnica de pirosequenciamento. Também foram determinadas as atividades das enzimas transaminase glutâmica oxalacética (TGO) e pirúvica (TGP), bem como da gama-glutamil transferase (GGT) no plasma por espectrofotometria UV/Visível. Cerca de 32\% dos voluntários consomem bebidas alcoólicas regularmente e $12 \%$ são fumantes. A concentração de $\mathrm{Pb}$-s em média foi de $19 \pm 10 \mu \mathrm{g} / \mathrm{dL}$ (variando de 1,8 a $48 \mu \mathrm{g} / \mathrm{dL}$ ) e Pb-p $0,56 \pm 0,64 \mu \mathrm{g} / \mathrm{dL}$ atingindo valores de até $4,0 \mu \mathrm{g} / \mathrm{dL}$. A maioria dos indivíduos, apresentou concentrações de ureia, creatinina, TGO, TGP e GGT dentro dos valores de referência. Em relação aos marcadores epigenéticos, foi observada uma associação inversa entre concentrações de $\mathrm{Pb}$-s e $\mathrm{Pb}$-p, ou seja, indivíduos que apresentavam altas concentrações do metal, tinham menor \% de metilação global do DNA. Em relação ao estudo das regiões promotoras dos genes $M T 2 A$ e $G C L C$, os resultados sugerem que o $\mathrm{Pb}$ não altera a metilação nas ilhas CpGs localizadas nas regiões promotoras dos genes $M T 2 A$ e GCLC, entretanto, foi capaz de induzir alterações no padrão de metilação global do DNA, fornecendo resultados acerca das possíveis interações entre o genoma e o metal.

Palavras-chave: chumbo, epigenética, interações gene-metais, toxicidade. 


\section{Introdução}

\subsection{O Chumbo $(\mathrm{Pb})$ e sua Toxicidade}

$\mathrm{O} \mathrm{Pb}$ é um metal tóxico, com baixo ponto de fusão, maleável, de baixa condutividade elétrica e tem capacidade de formar liga com outros metais (DE CAPITANI et al., 2009). Seu número atômico é 82 , massa atômica 207,21 e ponto de fusão, $337^{\circ} \mathrm{C}$ (CORDEIRO \& LIMAFILHO, 1995). O metal pode ser encontrado no ar, nos rios, lagos e oceanos, no solo e na cadeia alimentar. Portanto, a exposição ambiental ao $\mathrm{Pb}$ pode ocorrer tanto pela ingestão de alimentos contaminados, pela produção agrícola em solos contaminados ou irrigados com água contaminada, ou diretamente da ingestão, alimentos os quais tendem a incorporar $\mathrm{Pb}$ em maior ou menor proporção dependendo de variáveis, como por exemplo, a forma química do metal, idade e sexo (ATSDR, 2007; KELADA et al., 2001).

Em associação com outros elementos, o metal origina compostos tais como: sulfato de chumbo, arsenato de chumbo, dióxido de chumbo, chumbo-tetraetila, chumbo tetrametila, litargírio e zarcão (CORDEIRO \& LIMA-FILHO, 1995).

Para aumentar a octanagem, era comum em vários países a adição de chumbo tetraetila (CTE) na gasolina, caracterizando os automóveis como a principal fonte de emissão de $\mathrm{Pb}$ no ar até os anos 90. No Brasil, seu uso foi banido em 1989, porém boa parte da contaminação de solos existente atualmente pode-se considerar proveniente do uso de CTE na gasolina mesmo após vários anos passados (MINISTÉRIO DA SAÚDE, 2015).

$\mathrm{O} \mathrm{Pb}$ não desempenha nenhum papel fisiológico conhecido no organismo e, desta maneira, a exposição ao metal pode causar efeitos adversos em vários sistemas, tais como nervoso (SNC), renal, gastrointestinal, reprodutor, endócrino e hematopoiético (FLORA et al., 2012). Os sinais e sintomas ocasionados nas intoxicações por Pb são inespecíficos, uma vez que são comuns a diversas intoxicações. Ainda que incomuns, durante intoxicações agudas os indivíduos podem apresentar náuseas, dores abdominais, vômitos (os quais podem ter aspecto leitoso), sensação adstringente pronunciada na boca e gosto metálico. A intoxicação crônica, por outro lado, é mais comum e ocorre quando as concentrações do metal no sangue aproximam-se da faixa de 40 a $60 \mu \mathrm{g} / \mathrm{dL}$, sendo caracterizada por vômito persistente, encefalopatia, letargia, delírio, convulsões e coma (FLORA, et al., 2006; PEARCE, 2007).

As intoxicações por chumbo também podem induzir a eritose (AGUILAR-DORADO, et al., 2014), um fenômeno no qual os eritrócitos são removidos da circulação antes mesmo de completarem todos os estágios da morte celular programada (LANG et al., 2010), além da oxidação e depleção de glutationa (GSH) (AGUILAR-DORADO et al., 2014). Semelhante à exposição crônica ao $\mathrm{Pb}$, a exposição subcrônica pode estar associada a concentrações 
sanguíneas elevadas de ácido úrico e bilirrubina, e a ação pró-inflamatória das quimiocinas, além do aumento do estresse oxidativo (DOBRAKOWSK, et al., 2016; GHANWAT et al., 2016).

A toxicidade do $\mathrm{Pb}$ resulta, principalmente, de sua interferência no funcionamento das membranas celulares e enzimas, formando complexos estáveis com vários ligantes contendo enxofre, fósforo, nitrogênio ou oxigênio, como por exemplo, grupamento tiol (-SH), ácido fosfito $\left(-\mathrm{H}_{2} \mathrm{PO}_{3}\right)$, grupamento amino $\left(-\mathrm{NH}_{2}\right)$, grupamento hidroxila $(-\mathrm{OH})$ (ATSDR, 2007; SARYAN \& ZENZ, 1994). As interações bioquímicas do $\mathrm{Pb}$ com grupamentos -SH são consideradas de grande significado toxicológico, visto que o metal pode se ligar a diversos antioxidantes endógenos, como por exemplo, o tripeptídeo glutationa (GSH), as enzimas glutationa peroxidade (GPx) superóxido dismutase (SOD), catalase (CAT), dentre outras, ocasionando um desequilíbrio do estado redox celular e, desta maneira, elevar as concentrações de espécies reativas do oxigênio (EROs) e radicais livres, tais como peróxido de hidrogênio $\left(\mathrm{H}_{2} \mathrm{O}_{2}\right)$, superóxido $\left(\mathrm{O}_{2}{ }^{-}\right)$, radical hidroxil $\left(\mathrm{OH}^{*}\right)$ e oxigênio singlete $\left({ }^{1} \mathrm{O}_{2}\right)$ (HALLIWEL \& GUTTERIDGE, 1989; GURER et al., 2004; SUGAWARA et al., 1991). Este desequilíbrio entre as defesas antioxidantes celulares e as espécies oxidantes gera um estado pró-oxidante, ou também conhecido como estresse oxidativo, levando a danos em proteínas, lipídeos e DNA (JOMOVA \& VALKO, 2011; VALKO et al., 2005). Ainda, o Pb apresenta uma grande afinidade ao grupamento -SH da enzima ácido delta-aminolevulínico desidratase (ALAD), inativando-a; esta inibição resulta na redução da síntese do grupo heme e acúmulo de ácido aminolevulínico (ALA), podendo ocasionar diversos danos hematológicos (DUYDU et al., 2001; FARANT \& WIGFIELD, 1982; HOFFMAN et al., 2000). Além disso, está bem estabelecido que o ALA, em altas concentrações, atua como um pró-oxidante, causando também, distúrbios no status redox dos indivíduos (PATRICK, 2006).

$\mathrm{O} \mathrm{Pb}$ é absorvido principalmente através dos tratos gastrointestinal e respiratório; no caso das exposições ocupacionais a via respiratória é a mais importante (ATSDR, 2007; BAIRD, 2002; MOREIRA \& MOREIRA, 2004) e cerca de 95\% do Pb inalado atinge a corrente sanguínea (ATSDR, 2007). Uma vez absorvido, 99\% de todo o Pb-s está ligado aos eritrócitos e sua meia vida no sangue é de 30 dias. O metal livre no plasma (1\%) é então distribuído para os tecidos moles, como por exemplo, fígado, rins, cérebro, pulmões e baço, com meia vida de 40 dias. Embora apenas $1 \%$ do Pb esteja no plasma, é nesta fração do sangue em que o metal está mais biodisponível e assim, pode aumentar sua toxicidade. O metal também é distribuído para os tecidos calcificados, onde a meia vida é de cerca de 30 anos (LIU et al. 2010), portanto, os ossos formam os principais sítios de armazenamento do metal, 
chegando a constituir 90\% de todo o metal presente no organismo (POUNDS et al., 1991; RABINOWITZ, 1991). Mesmo após anos do término da exposição do indivíduo ao metal, o $\mathrm{Pb}$ pode ser deslocado do tecido ósseo para a corrente sanguínea, tanto por mecanismos fisiológicos, tais como a gravidez (GULSON et al., 2003; MANTON et al., 2003), quanto por patologias, como por exemplo, a osteoporose (SILBERGELD et al., 1988; TSAHÍ et al., 2001).

Em relação ao seu metabolismo e excreção, cerca de $2 / 3$ do $\mathrm{Pb}$ absorvido é eliminado pela urina e o restante pelas fezes. Em ambas as vias de eliminação, o metal pode sofrer reabsorção nos túbulos renais distais e através do sistema entero-hepático. $\mathrm{O} \mathrm{Pb}$ também é eliminado através do cabelo, suor, saliva e unhas, mas a taxa de eliminação destes sistemas é virtualmente nula, quando comparada aos sistemas renal e hepático (GOYER \& CLARKSON, 2001).

A Figura 1 ilustra a cinética do metal no organismo, mostrando que alterações em um ou mais eventos relacionados à absorção, distribuição, metabolismo e excreção (ADME) do $\mathrm{Pb}$, podem alterar a relação entre a exposição e as concentrações do metal no sangue, plasma, urina e/ou fezes e, assim, modular os efeitos adversos causados pela exposição ao $\mathrm{Pb}$.

Figura 1 - Esquema da toxicocinética do $\mathrm{Pb}$.

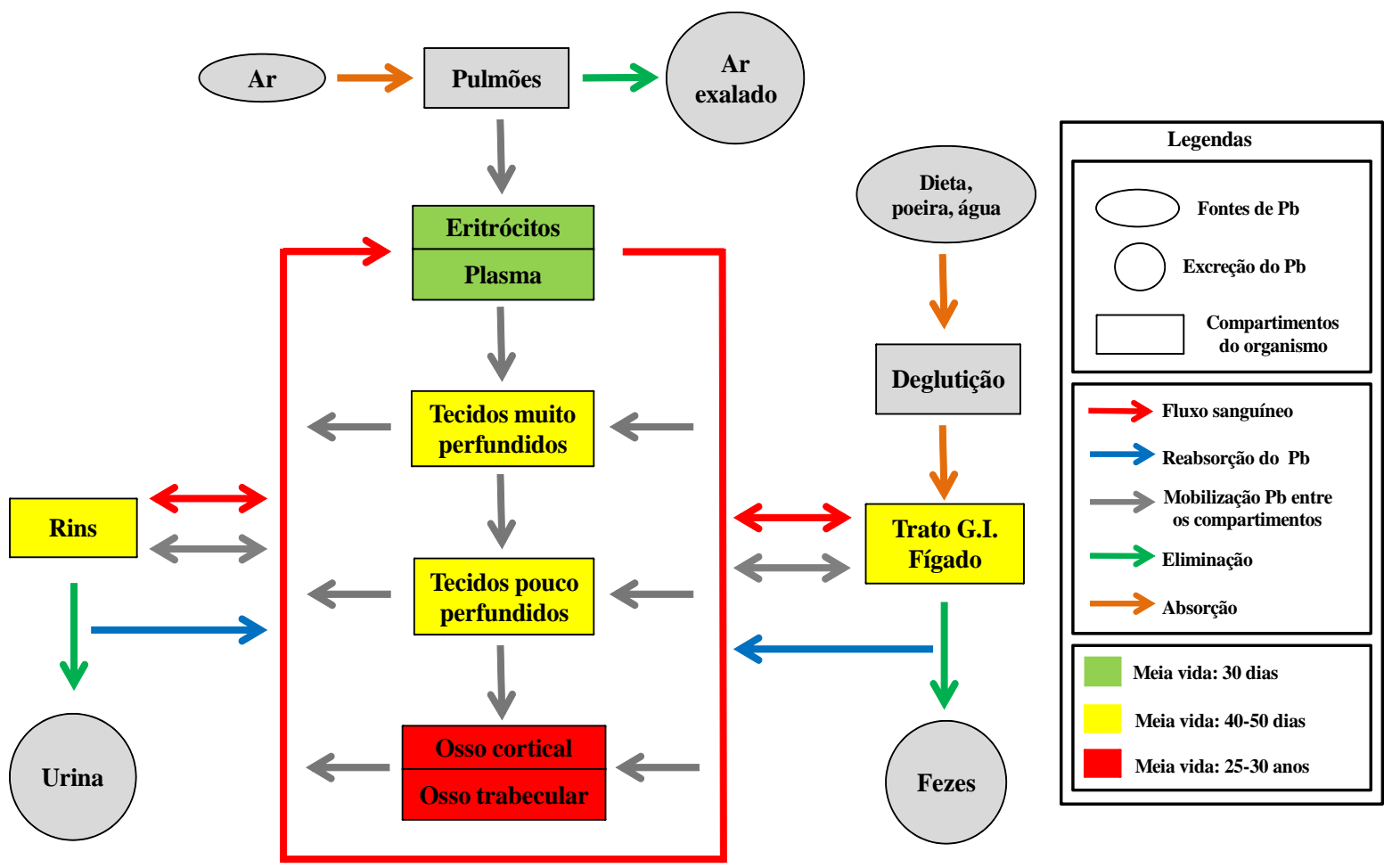

Fonte: Modificado de O’Flaherty, 1998. 


\subsection{Exposição ocupacional ao $\mathbf{P b}$}

$\mathrm{O} \mathrm{Pb}$ é utilizado em indústrias químicas e de construção, eletroeletrônicas (soldas e ligas), na proteção contra raios-x, maquiagem e corantes (MINISTÉRIO DA SAÚDE, 2015), como componente da manufatura da borracha, como ingrediente de tintas, constituinte de vitrificados, esmaltes e em fábricas de baterias (PAOLIELLO \& DE CAPITANI, 2003; DE CAPITANI et al., 2009).

No Brasil, o Pb é utilizado em larga escala nas fabricações de baterias chumbo-ácidas. Já nos países desenvolvidos, os riscos de contaminação foram rigorosamente controlados e estudados, diferentemente dos países em desenvolvimento. (PAOLIELLO \& DE CAPITANI, 2007; MINOZZO et al., 2009). A principal fonte de exposição ocupacional são as fábricas de baterias automotivas, seguida das indústrias de pigmento e o setor eletroeletrônico (soldas e ligas) (DE CAPITANI et al., 2009).

A Organização Mundial da Saúde (OMS) reconhece o Pb como um dos elementos químicos mais perigosos à saúde humana. Em paralelo a isso, na revisão das monografias de 2006, a "International Agency for Research on Cancer - IARC", alterou a classificação do Pb e seus compostos de 2B (possivelmente carcinogênica para humanos) para a categoria $2 \mathrm{~A}$ (provavelmente carcinogênico em humanos), demonstrando que existem evidências suficientes em estudo realizados em animais e evidências limitadas em humanos acerca da carcinogenicidade do $\mathrm{Pb}$.

Segundo o Ministério da Saúde (2015) a utilização do chumbo vem sendo restrita devido ao seu potencial tóxico. O quadro de exposição crônica ao $\mathrm{Pb}$ que é desenvolvido por trabalhadores expostos é conhecido como saturnismo.O saturnismo é caracterizado por ser uma doença que ocorre em resposta à toxicidade causada pelo chumbo ao organismo, o qual interage em reações metabólicas. O diagnóstico baseia-se na positividade obrigatória dos três fatores: (A) quadro clínico compatível com a exposição; (B) exposição ocupacional; e (C) comprovação de concentrações elevadas de chumbo no sangue (DE CAPITANI et al., 2009).

Neste contexto, o Ministério do Trabalho e Emprego do Governo Federal do Brasil, estabeleceu diretrizes com o objetivo de minimizar os efeitos adversos causados pela exposição ao metal. A Norma Regulamentadoras no 15 (NR-15, Portaria MTb nº 3.214, de 08 de junho de 1978) estabeleceu os limites de tolerância em relação à sua concentração máxima no ambiente de trabalho, fixado em $100 \mu \mathrm{g} / \mathrm{m}^{3}$ de ar (para jornadas de 48 horas semanais). Ainda, de acordo com a NR-15, a exposição ao Pb em fábricas de baterias é classificada como "insalubridade de grau máximo”. Já a Norma Regulamentadora nº (NR-7, Portaria GM n. ${ }^{\circ} 3.214$, de 08 de junho de 1978, modificada pela Portaria SSST n. ${ }^{\circ}$ 24, de 29 de dezembro de 1994) estabeleceu os 
bioindicadores de exposição e efeito, para monitoramento biológico dos trabalhadores expostos e são eles: concentrações de $\mathrm{Pb}$ no sangue $(\mathrm{Pb}-\mathrm{s})$ e do ácido delta-aminolevulínico urinário (ALA-U), respectivamente. Alternativamente, a determinação da zincoprotoporfirina no sangue (ZPP) também pode ser utilizada como um indicador biológico de efeito. Além disso, a NR-7 estabeleceu os Índices Biológicos Máximos Permitidos (IBMP) em trabalhadores expostos ao metal, ou seja, as concentrações máximas permitidas de Pb-s, ALA-U e ZPP: $60 \mu \mathrm{g} / \mathrm{dL}, 10$ $\mathrm{mg} / \mathrm{g}$ de creatinina e $100 \mu \mathrm{g} / \mathrm{dL}$, respectivamente. Ainda, a NR-7 apresenta os valores denominados de referência (VR), de $\mathrm{Pb}$ no ambiente de trabalho de até $40 \mu \mathrm{g} / \mathrm{dL}$ de $\mathrm{Pb}$-s, até 4,5 mg de ALA-U/g creatinina e até $40 \mu \mathrm{g} / \mathrm{dL}$ de ZPP.

Para efeitos de comparação, a Administração de Segurança e Saúde Ocupacional (OSHA, EUA), determina que os valores permissíveis para o ambiente de trabalho não devam exceder a concentração de $30 \mu \mathrm{g} / \mathrm{m}^{3}$ de ar; já em relação ao bioindicador de exposição, $\mathrm{Pb}$-s, as concentrações não devem ultrapassar $40 \mu \mathrm{g} / \mathrm{dL}$; valores estes utilizados como "referência" em populações brasileiras não expostas. A OSHA não estabelece limites para concentrações de ALA-U e ZPP, uma vez que a relação entre a exposição ao metal e as concentrações destes biomarcadores não estão muito bem estabelecidas e podem apresentar amplas variações. Comparando-se as legislações americana e brasileira, um enorme contraste é observado em relação aos limites das concentrações de $\mathrm{Pb}$ no ambiente. Como mencionado, no Brasil a legislação estabelece a concentração de $100 \mu \mathrm{g}$ de $\mathrm{Pb} / \mathrm{m}^{3}$; esta mesma concentração, de acordo com o Instituto Nacional de Segurança e Saúde Ocupacional (NIOSH, EUA), é caracterizada como "concentrações imediatamente perigosas à vida ou à saúde". A discrepância entre estes dados demonstra a necessidade de uma revisão da legislação brasileira, que se encontra defasada, pois a última atualização a respeito foi publicada em 1994 (Ministério do Trabalho e Emprego do Governo Federal do Brasil, NR-7, Portaria GM n. ${ }^{\circ} 3.214$, de 08 de junho de 1978, modificada pela Portaria SSST n. ${ }^{\text {o } 24, \text { de }} 29$ de dezembro de 1994).

Embora diversos estudos relacionados ao biomonitoramento e aos efeitos tóxicos induzidos pela exposição ao Pb tenham sido conduzidos (BERGDAHL \& SKERFVING, 2008; GARCÍA-LESTÓN et al., 2012; GARÇON et al., 2007). Estudos realizados na cidade de Bauru, SP, entre 1985 e 1987 identificaram seiscentos casos de saturnismo entre trabalhadores de fábricas de baterias (CORDEIRO, 1988). Melo Mattos e colaboradores (1994) estudaram 1.520 trabalhadores na região metropolitana de Belo Horizonte e observaram que $70 \%$ tinham $\mathrm{Pb}$ acima de $40 \mu \mathrm{g} / \mathrm{dL}$ e destes, 38\% estavam acima de $60 \mu \mathrm{g} / \mathrm{dL}$. No estudo realizado por Araujo et al. (1999), trabalhadores de fábricas de baterias do setor de montagem com mais de seis meses de exposição apresentaram concentrações de $\mathrm{Pb}$-s na faixa de 38-60 $\mu \mathrm{g} / \mathrm{dL}$ (média = 
$48 \mu \mathrm{g} / \mathrm{dL}$ ). Menegotto e Paoliello (2001) encontraram um resultado semelhante em outra fábrica de baterias, onde a média de $\mathrm{Pb}$-s foi de $45 \mu \mathrm{g} / \mathrm{dL}$. Em um trabalho prévio do nosso grupo, Silva (2008) relatou uma média de 64,4 $\mu \mathrm{g} / \mathrm{dL}$ em trabalhadores ocupacionalmente expostos ao metal, em fábricas de baterias na cidade de Bauru-SP.

Em 2012, o Programa Nacional de Toxicologia (NTP, DHHS, EUA), publicou uma série de monografias demonstrando que há evidências suficientes relacionados efeitos adversos à saúde em adultos com concentrações sanguíneas de $\mathrm{Pb}$ menores que $10 \mu \mathrm{g} / \mathrm{dL}$ (tais como aumento da pressão arterial e tremor) e em crianças com concentrações menores que $5,0 \mu \mathrm{g} / \mathrm{dL}$ (efeitos renais e de desenvolvimento), o que reforça ainda mais a necessidade de uma ampla e constante revisão das legislações vigentes.

\subsection{Interações gene-metais}

As variações genéticas, como por exemplo, os polimorfismos de um único nucleotídeo, de genes que regulam a toxicocinética e a toxicodinâmica de metais influenciam na retenção e acumulação do metal no organismo, bem como os efeitos tóxicos. Os eventos epigenéticos, que regulam a expressão gênica, também têm sido identificados como alvos para a modulação da toxicidade do metal. (BROBERG et al., 2014).

\subsubsection{Interação gene-chumbo}

Em uma revisão, Kim (2014) demonstrou que interações genes-metal podem modificar a toxicidade ou ter efeito protetor para a toxicidade do chumbo. Por exemplo, os genes $A L A D$ (Ácido Delta Aminolevulínico Desidratase) e VDR (Receptor de Vitamina D), têm se mostrado genes de suscetibilidade. Outro trabalho realizado sugere que variações em outros genes podem também modular a toxicocinética e, consequentemente, os efeitos adversos relacionados ao metal, tais como genes da Família de Carreadores de Soluto (do inglês, solute-carrier gene $S L C \mathrm{~s}$ ) - além de estarem associados com o transporte de $\mathrm{Pb}$ - e DNA metiltransferases (DNMTs) (SCHNEIDER et al., 2013; WITHFIELD et al., 2007; 2010).

Estudos prévios mostram que outros gene também podem estar associados com ADME e toxicidade do $\mathrm{Pb}$ e de outros metais, por exemplo o gene MT2A (Metalotioneína 2A) (FERNANDES et al., 2016; KAYAALTI et al., 2011), GSTP1 (Glutationa S-Transferase 1) (KHANSAKORN et al., 2011) GGT1 (Gama Glutamil-Transferase 1) (KHAN et al., 2008) GPxl (Glutationa Peroxidase 1), GSR (Glutationa Redutase) (HUNAITI et al., 1995), GSS (Glutationa Sintetase) (ENGSTRÖM, 2008), GCLC (Subunidade Catalítica de Glutamato-Cisteína Ligase) $e$ GCLM (Subunidade Modificadora de Glutamato-Cisteína Ligase) (BARCELOS et al., 2015). 
Recentemente, um estudo realizado por Fernandes et al. (2016) com a mesma população estudada no presente projeto avaliou os efeitos genéticos do polimorfismo do gene $M T 2 A$ (polimorfismo de nucleotídeo único rs 10636; $\mathrm{C} \rightarrow \mathrm{G}$ ), sustentando a hipótese de que polimorfismos em genes relacionados ao transporte de $\mathrm{Pb}$, como MTs, podem modular as concentrações do metal no organismo e, consequentemente, os efeitos adversos à saúde induzidos pela exposição ao metal.

\subsubsection{Mecanismos epigenéticos}

A epigenética é o estudo de alterações fenotípicas herdáveis que não alteram a sequência do DNA (LIEB et al., 2006) e está envolvida tanto em processos fisiológicos quanto em processos patológicos (BONETTA, 2008), como o câncer (FEINBERG, 2006).

As modificações epigenéticas atuam como reguladoras da expressão gênica e podem ser influenciadas por fatores ambientais, como a dieta, estresse, toxicantes (FAULK; DOLINOY, 2011), e metais como o Pb, como demonstrado por estudos anteriores (LI et al., 2016; SEN et al., 2015a; NYE et al., 2015). As modificações epigenéticas têm sido classificadas em quatro classes: 1- Conformação da cromatina e posicionamento dos nucleossomos; 2- Modificações do DNA (metilação); 3- Modificações pós-traducionais de histonas; 4- Regulação gênica associada aos RNA não codificadores (ncRNAs) (FINGERMAN et al., 2013).

A metilação do DNA é uma modificação química, na qual ocorre a adição de um grupamento metil $\left(-\mathrm{CH}_{3}\right)$, de forma covalente, na citosina na posição 5' a um resíduo de guanina ( $\mathrm{CpG}$ - citosina ligação fosfato guanina), transformando-a em 5mC (BIRD, 2011), como mostra a figura 2. O DNA é metilado pela ação das enzimas DNMTs (Metiltransferases de DNA), onde o doador universal do grupamento metil é a SAM (S-adenosil-L-metionina), que é sintetizada a partir de doadores de metil, como metionina e colina, e co-fatores como a vitamina B12 e ácido fólico. As DNMTs catalisam a transferência de um grupamento metil da SAM para a citosina. A 5mC (5-metil-citosina) constitui cerca de 1\% de todas as bases de DNA (TOST, 2010).

O silenciamento gênico decorrido do processo de metilação pode ocorrer de duas formas: 1- silenciamento direto (quando a metilação do DNA impede a ligação de fatores de transcrição ou afeta a estrutura da cromatina); 2- silenciamento indireto (quando a metilação do DNA reúne as proteínas ligadoras de metil, formando complexos repressores) (MUTHUSAMY et. al., 2010). Em regiões repetitivas, a citosina metilada sofre altas taxas de mutação, pois ela é convertida em timina por desaminação hidrolítica espontânea (SHEN et. al., 1994). 
Figura 2 - Estrutura química do processo de metilação de uma citosina por meio da enzima DNA-metiltransferase (DNTM).

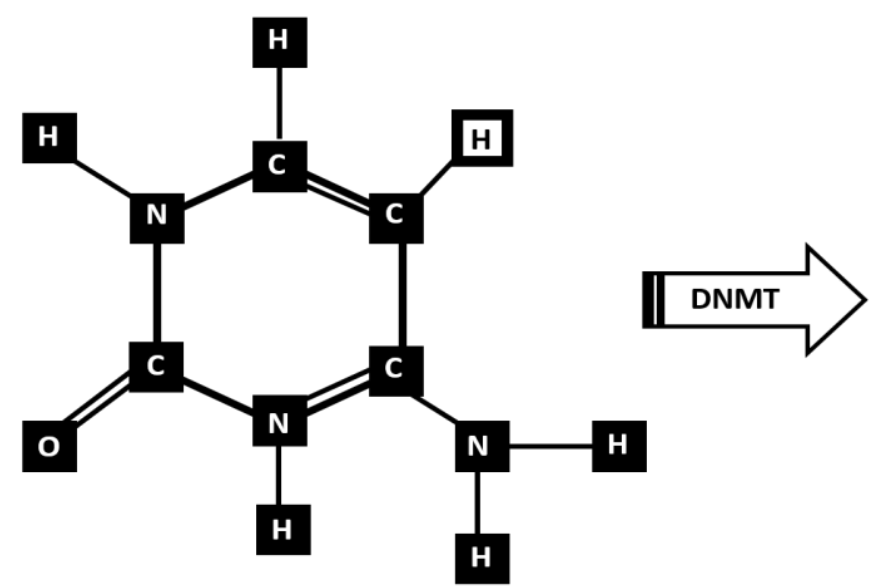

Citosina

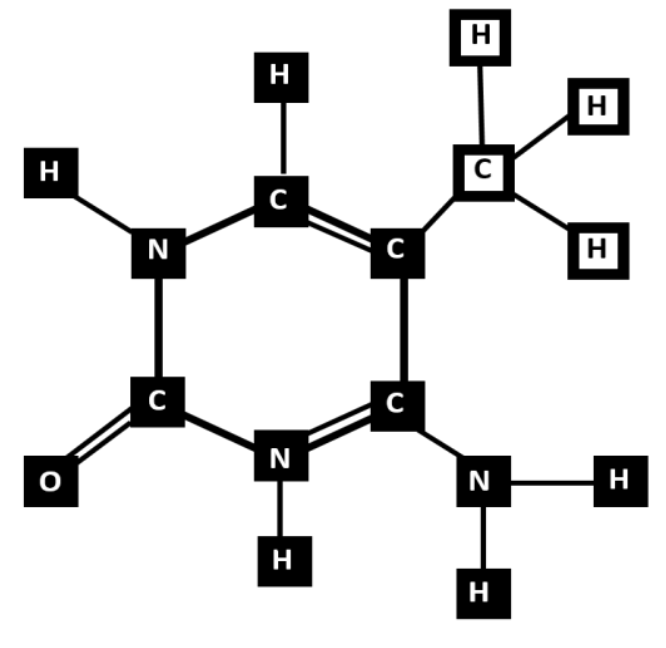

5-metil-citosina

Fonte: Adaptado do livro "EPIGENÉTICA: Bases moleculares, efeitos na fisiologia e na patologia, e implicações para a produção animal e a vegetal" (NICIURA E SARAIVA, 2015).

O trabalho de Li (2013) associou a metilação do DNA com o desenvolvimento da toxicidade causada pela exposição ao $\mathrm{Pb}$. $\mathrm{O}$ estudo envolveu trabalhadores de fábricas de baterias e voluntários saudáveis com idades correspondentes ao grupo exposto, com o objetivo de determinar a relação entre o LINE-1 (long interspersed nuclear elements) e a porcentagem de metilação. Foi observada uma relação inversa entre a concentração de $\mathrm{Pb}$ e a metilação do DNA nos indivíduos expostos, ou seja, quanto maior a exposição ao metal, menor a \% de metilação do DNA. No estudo de Sen (2015b) investigou-se a relação entre a exposição ao $\mathrm{Pb}$ e as modificações 5mC (5-metilcitosina) e 5hmC (5-hidroximetilcitosina), presentes nas ilhas CpGs de genes no DNA de células do cordão umbilical e células embrionárias humanas. Foram identificados vários loci genômicos com $5 \mathrm{mC}$ e $5 \mathrm{hmC}$, sugerindo ser um potencial biomarcador da exposição pré-natal ao $\mathrm{Pb}$.

Pilsner e colaboradores (2009), por sua vez, também estudaram a exposição ao $\mathrm{Pb}$ na fase pré-natal, verificando a influência da exposição na metilação do DNA de células do cordão umbilical. Foi concluído que a exposição pré-natal ao $\mathrm{Pb}$ é inversamente associada com a metilação do DNA em células sanguíneas do cordão umbilical, sugerindo que a exposição ao metal durante o período gestacional pode influenciar a programação epigenética a longo prazo.

Mais recentemente, outros grupos de pesquisa direcionaram seus esforços a fim de estabelecer associações entre efeitos epigenéticos e a exposição a metais; do mesmo modo, estão melhor estabelecidas as associações epigenéticas entre $\mathrm{As}, \mathrm{Hg}, \mathrm{Cd}$ do que ao $\mathrm{Pb}$ (CHENG et al., 2012; MARTINEZ-ZAMUDIO \& HA, 2011). Wright e colaboradores (2010) observaram que as 
concentrações de $\mathrm{Pb}$ na patela estavam inversamente associadas com a metilação global do DNA, em homens adultos americanos. Li et al. (2011) demonstraram que a exposição ao $\mathrm{Pb}$ diminuiu a expressão gênica da $A L A D$, através do aumento da metilação na região promotora do gene, em trabalhadores de fábrica de baterias, na China. Até o momento, esses são os únicos trabalhos que associaram efeitos epigenéticos e exposição ao metal, em seres humanos.

Existem vários estudos envolvendo a exposição a outros metais e seus efeitos epigenéticos, tais como a relação da exposição ao $\mathrm{Cd}$ e os mecanismos epigenéticos envolvidos em modelos in vitro de células da próstata e células uroteliais (SEVERSON et al, 2012), em células sanguíneas maternas e de cordão umbilical de 17 mães e 17 bebês, onde foi encontrado hiper e hipometilação (SANDERS et al, 2014). Também, foram relacionados à exposição ao arsênio As à hipermetilação do DNA de genes supressores tumorais de pessoas expostas ao metal na Índia (CHANDA et al., 2006); à hipometilação de queratinócitos cultivados in vitro (REICHARD et al, 2007), e de modelos de células epiteliais da próstata in vitro (COPPIN et al, 2008). Já em relação ao Hg, existem efeitos epigenéticos envolvendo a hipermetilação no DNA de células sanguíneas de mulheres submetidas à estimulação ovariana (HANNA et al, 2012) e hipometilação em células da mucosa bucal de profissionais de odontologia (GOODRICH et al, 2013). Segundo Kim et al (2014), o Pb é um dos materiais tóxicos de maior importância, porém, a concentração de segurança a respeito do $\mathrm{Pb}$ não está bem estabelecida, pois, mesmo em um baixo nível de exposição, ainda apresenta elevada toxicidade.

Hou e colaboradores (2011) enfatizaram a importância de se estudar a interação entre a epigenética e a exposição aos metais, do ponto de vista que, estudos futuros podem ajudar a elucidar a distribuição e a participação de cada um deles a fim de determinar os efeitos no desenvolvimento de doenças. Segundo Baccarelli e Bollati (2009), a epigenética tem um potencial significativo para o desenvolvimento de marcadores biológicos para indivíduos expostos a metais tóxicos e para classificar o risco de suscetibilidade de desenvolver doenças.

Segundo Britto e colaboradores (2014), os metais tóxicos exercem muitos efeitos colaterais à saúde e, por este motivo podem existir alterações na expressão gênica. Isto mostra que as modificações epigenéticas, atuam como mecanismos reguladores, e é de primordial importância atualmente. Em uma revisão de literatura, Fragou e colaboradores (2011) concluíram que as modificações epigenéticas (metilação do DNA e modificação de histonas) têm sido amplamente associadas à exposição aos metais tóxicos. De acordo com Martinez-Zamudio e Ha (2011), o acúmulo de evidências mostra claramente que as exposições aos metais tóxicos levam à indução e alteração de marcas epigenéticas em estudos tanto experimentais quanto epidemiológicos. 
Recentemente, um estudo realizado com ratos expostos ao $\mathrm{Pb}$ evidenciaram que as modificações epigenéticas são afetadas pela exposição durante o desenvolvimento e podem desempenhar um papel importante na mediação do aumento das proteínas cerebrais que estão intimamente relacionadas à doença de Alzheimer (EID et al., 2016).

Assim, podemos perceber que é de extrema importância e relevância estudar a fundo qual a influência que exposição ao $\mathrm{Pb}$ exerce sobre o padrão de metilação do DNA e os mecanismos que estão associados a estes eventos.

\subsubsection{Genes GCLC e $M T 2 A$}

O gene GCLC (Gene ID: 2729) é localizado no cromossomo 6p12.1 e possui um importante papel na codificação da glutamato cisteína ligase (GCL), uma proteína dimérica composta pelas subunidades modificadora (GCLM) e catalítica (GCLC), sendo esta última codificada pelo gene em questão (FRANKLIN et al, 2009). A subunidade GCLC é a responsável por catalisar a ligação entre o grupamento amina da cisteína e o grupamento carboxila do glutamato para síntese da GSH, importante antioxidante endógeno (GRIFFITH et al, 1999; YANG et al, 2007). Esta é a maior das duas subunidades (637 aminoácidos, cerca de $73 \mathrm{kd}$ ) e nos seres humanos o gene GCLC é composto por 16 éxons e abrange aproximadamente $48 \mathrm{~kb}$ da sequência de DNA (FRANKLIN et al., 2008).

Os níveis de GCLC são de extrema importância para determinar a atividade de GCL (LEE et al., 2006; NEUROHR et al., 2003). Diversas condições podem regular a pré-tradução do $G C L C$, dentre elas: linhagens celulares tumorais que são resistentes a fármacos, além do estresse oxidativo, que estão associados com o aumento dos níveis de GSH e da atividade de GCL (MULCAHY et al., 1994; YAMANE et al., 1998); a insulina sob condição glicêmica alterada (LANGSTON et al., 2008) e tratamentos com antioxidantes (EATON \& HAMEL, 1994; LIU et al., 1994). Desta maneira, é esperado que a expressão de GCLC seja mais intensa em situações onde a formação de GSH é estimulada, como ocorre em resposta a um evento de estresse oxidativo (GRIFFITH et al, 1999; RAHMAN \& MACNEE, 2000).

O gene MT2A (Gene ID: 4502) é localizado no cromossomo 16q13 e tem como função a codificação das MTs, que são proteínas plasmáticas de baixo peso molecular (em torno de 0,515 kd). São formadas de aproximadamente $30 \%$ de cisteínas e possuem muitos grupos tióis os quais tem alta afinidade com íons metálicos. A afinidade de ligação dos resíduos de cisteínas com metais segue a seguinte ordem: $\mathrm{Zn}$ (II) $>\mathrm{Pb}$ (II) $>\mathrm{Cd}$ (II) $>\mathrm{Cu}$ (I) $>\mathrm{Ag}$ (I) $>\mathrm{Hg}$ (II) $>\mathrm{Bi}$ (III); neste contexto, é plausível que haja competição principalmente entre $\mathrm{Zn}$ e $\mathrm{Pb}$, e desta maneira, a fração plasmática de $\mathrm{Pb}$ aumente, o que pode impactar diretamente a relação entre 
$\mathrm{Pb}-\mathrm{p} / \mathrm{Pb}$-s, aumentando ou diminuindo a toxicidade do metal (HALL, 2002; RAUDENSKA et al., 2013).

Existem quatro subfamílias das MTs expressas em seres humanos: MT1, MT2, MT3 e MT4 e, em sua revisão, Raudenska e colaboradores (2014) identificaram que polimorfismos (SNPs) em $M T s$ - especialmente no gene $M T 2 A$ - estão relacionados com patologias como síndromes metabólicas, incluindo diabetes, aterosclerose e hipertensão. As características genéticas individuais das MTs são de extrema importância em processos patológicos e fisiológicos no que diz respeito à detoxificação dos metais (RAUDENSKA et al., 2014).

Portanto, é presumível que variações nessas proteínas possam alterar a relação entre a exposição e toxicidade induzida pelo $\mathrm{Pb}$. Neste sentido, a Tabela 1, mostra os genes selecionados, no presente estudo, para a avaliação da interação epigenoma- $\mathrm{Pb}$.

Tabela 1 - Dados referentes aos genes que foram utilizados para a análise das expressões gênicas e dos padrões de metilação das regiões promotoras escolhidas para o presente estudo.

\begin{tabular}{cccccc}
\hline Gene & Gene ID & Tamanho $(\mathbf{p b})$ & Início & Final & \% CG \\
\hline$M T 2 A$ & 4502 & 779 & 56.641 .947 & 56.642 .725 & 61,6 \\
GCLC & 2729 & 1.263 & 53.408 .934 & 53.410 .196 & 66,3 \\
\hline
\end{tabular}

Os dados foram obtidos no banco de dados Epigenomics (NCBI).

\subsubsection{Técnicas para análises de metilação}

Atualmente diversas técnicas são utilizadas com a finalidade de se avaliar a metilação do DNA e, entre as mais conhecidas estão: COBRA (Combined Bisulfite Restriction Analysis), LINE-1 (Long Interspersed Nucleotide Elements), MS-HRM (Methylation Sensitive High Resolution Melting) e o Pirosequenciamento.

A técnica COBRA usa a amplificação do DNA tratado com bissulfito de sódio (com iniciadores que não diferem o fragmento metilado de não-metilado), seguido por digestão com enzima de restrição (que revela nos produtos de PCR diferenças de sequências dependentes de metilação) (XIONG E LAIRD, 1997). É um método semiquantitativo e altamente sensível, porém pode gerar resultados falso-positivos em caso de digestão enzimática incompleta, por exemplo. (BENHATTAR E CLÉMENT, 2004).

Na técnica de MS-HRM, os iniciadores na PCR amplificam tanto amostras metiladas quanto não metiladas, e uma curva-padrão com proporções conhecidas de metilação é incluída durante a amplificação para funcionar como um controle da reação. A porcentagem de metilação é determinada com base nas modificações na temperatura de dissociação dos fragmentos de DNA. (LI, et al., 2010; WOJDACZ, et al., 2008). 
Os níveis de metilação em LINE-1 podem ser avaliados de forma alternativa que envolve a conversão do DNA por bissulfito de sódio seguido da amplificação por PCR de sequências conservadoras, porém, a verificação da porcentagem de metilação é dada de maneira global, sem distinção de sua posição no genoma. Nesta técnica quantidades mínimas de DNA são necessárias para sua amplificação e análise (OGINO et al., 2008; HUR et al., 2014; ZHU et al., 2014)

O pirosequenciamento é uma técnica que monitora quantitativamente a incorporação em tempo real de nucleotídeos através da conversão enzimática do pirofosfato. As medidas quantitativas são de extrema importância quando se tratam de análises de metilação do DNA em situações de desenvolvimento de alguma patologia, como o câncer. Análises dos padrões de metilação do DNA por pirosequenciamento combinam um protocolo de reações simples com medidas reproduzíveis e precisas do grau de metilação em vários CpGs que são determinados a partir da razão de C/T (TOST, 2007; KURDYUKOV et al., 2017).

Ao mesmo tempo que a técnica permite analisar diversos $\mathrm{CpGs}$ em uma só corrida, também há a possibilidade de análise de sítios CpGs individuais e específicos. O pirosequenciador possui um controle de qualidade interno, além de ter um limite de detecção de aproximadamente 3\% (TOST et al., 2003; DEJEUX et al., 2007). Em comparações com vários laboratórios, o pirosequenciamento se mostrou como uma das técnicas mais precisas e reprodutíveis para a análise de metilação de DNA, além de ser uma das mais adequadas para testes de diagnóstico (THE BLUEPRINT CONSORTIUM, 2016; QUILLIEN, 2016).

O pirosequenciamento também possui suas limitações: uma delas refere-se à baixa eficiência na detecção de homopolímeros longos (repetição de nucleotídeos), o que pode resultar em erros de sequenciamento (HUSE et al., 2007). Outra limitação inclui o alto custo dos iniciadores biotinilados, bem como de reagentes para o processamento pós-PCR, além do custo de manutenção do equipamento utilizado (WOLFORD \& YEATTS, 2005).

\section{Objetivos}

\subsection{Objetivos Gerais}

a) Determinar as concentrações de $\mathrm{Pb}$-s e $\mathrm{Pb}$-p de trabalhadores de fábricas de baterias automotivas do Paraná expostos ao metal de forma ocupacional, e correlacionar com variáveis obtidas através dos questionários;

b) Quantificar os parâmetros bioquímicos: gama-glutamil transferase (GGT), transaminase glutâmica oxalacética (TGO), transaminase glutâmica pirúvica (TGP), ureia (UR) e creatinina (CR). 
colaboradores (2008) foi o único que objetivou avaliar o impacto da exposição ao metal sobre o sistema enzimático das GCLs.

No presente estudo, não foi evidenciada nenhuma associação entre a exposição ao metal ( $\mathrm{Pb}$-s e $\mathrm{Pb}-\mathrm{p})$ e alterações no padrão de metilação da região promotora do gene $G C L C$. Uma das possíveis hipóteses para esta observação é de que existam mecanismos adjacentes que controlam a expressão deste, uma vez que ele é muito expresso em função de respostas ao estresse oxidativo (GRIFFITH et al, 1999; RAHMAN \& MACNEE, 2000). A plataforma MethHC: A database of DNA Methylation and gene expression in Human Cancer reúne diversos dados acerca do padrão de metilação de milhares de genes e os compara entre indivíduos com determinado tipo de câncer e seus respectivos grupos controle. Pode ser visto que a \% de metilação do gene GCLC (transcritos NM_001197115 e NM_001498) em indivíduos saudáveis está entre 0,050 e 0,10 \%, enquanto que em indivíduos com cânceres, a porcentagem de metilação neste gene alcança valores acima de 0,60\%. Como pode ser observada, a porcentagem de metilação na região promotora deste gene foi de $0,83 \pm 0,38 \%$, ou seja, valores muito maiores que dos indivíduos saudáveis, o que pode sugerir que a exposição ao metal, independentemente da concentração, seja capaz de induzir silenciamento gênico por mecanismos de metilação do material genético. Entretanto, é importante ressaltar de que este é o primeiro estudo que objetivou avaliar o padrão de metilação da região promotora do gene GCLC em indivíduos expostos ao $\mathrm{Pb}$ e, portanto, não se tem conhecimento acerca do "background" genéticos destas populações e associações diretas com mecanismos de carcinogênese devam ser evitadas para que não haja má interpretação dos dados. Sendo assim, estudos que envolvam mais genes envolvidos na síntese do tripeptídeo glutationa, bem como análise de suas interações gene-gene e gene- $\mathrm{Pb}$ poderão esclarecer as possíveis interações entre estas variáveis, bem como estudos que visem avaliar diretamente a expressão destes genes.

\section{Conclusões}

De acordo com os dados obtidos no presente trabalho é possível concluir que:

a) $\quad \mathrm{A}$ exposição ao $\mathrm{Pb}$ não altera significativamente parâmetros bioquímicos associados à toxicidade renal (ureia e creatinina) e hepática (TGO, TGP e GGT);

b) A exposição ao metal induz diminuição no padrão de metilação global do DNA dos trabalhadores expostos, porém não induz alterações no padrão de metilação das regiões promotoras dos genes MT2A e GCLC. 


\section{Referências}

AGUILAR-DORADO, C. et al. Eryptosis in lead-exposed workers. Toxicology and Applied Pharmacology. 281: 195-202, 2014.

ARAÚJO, U. et al.Avaliação da exposição ocupacional ao chumbo: proposta de uma estratégia de monitorização para a prevenção de efeitos clínicos e sub-clínicos. Cadernos de Saúde Pública. Rio de Janeiro, 15(1):123-131, 1999.

ATSDR. Agency for Toxic Substances and Disease Registry. Toxicological profile for lead. U.S. Department of Health and Human Services. Public Health Service. 2007.

BACCARELli, A., BOLLATI V. Epigenetics and environmental chemicals. Current Opinion in Pediatric. 21(2): 243-251, 2009.

BAIRD, C. Metais pesados tóxicos. In: Química Ambiental 2aed. São Paulo: Bookman: 403-439, 2002.

BARCELOS, G. R. M. et al. Effects of genetic polymorphisms on antioxidant status and concentrations of the metals in the blood of riverside Amazonian communities co-exposed to $\mathrm{Hg}$ and $\mathrm{Pb}$. Environmental Research. 138: 224-232, 2015.

BATISTA, B. L. et al. Exploiting dynamic reaction cell inductively coupled plasma mass spectrometry for sequential determination of trace elements in blood using a dilute-and-shoot procedure. Analytica Chimica Acta. 639(1-2): 13-18, 2009a.

BATISTA, B. L. et al. Reference concentrations for trace elements in urine for the Brazilian population based on ICP-MS with a simple dilute-and-shoot procedure. Journal of the Brazilian Chemical Society. 20: 1406-1413, 2009 b.

BECKETT, W. S., NORDBERG, G.F., CLARKSON, T.W. Routes of exposure, dose, and metabolism of metals. In: Nordberg, G.F., Fowler, B., Nordberg, M., Friberg, L.T. (eds) Handbook on the toxicology of metals, 3rd. Academic Press, San Diego, pp. 39-64, 2007.

BENHATTAR, J., CLÉMENT, G. Methylation-sensitive single-strand conformation analysis. In: TOLLEFSBOL, T. O. (Ed.). Epigenetics protocols. New Jersey: Human Press. 181-193, 2004.

BERGDAHL, I. A; SKERFVING, S. Biomonitoring of lead exposure-alternatives to blood. Journal of Toxicology and Environmental Health A. 71(18):1235-43, 2008.

BIRD, A. The Dinucleotide CG as a Genomic Signalling Module. Journal of Molecular Biology. 409(1): 47-53, 2011.

BOLLATI, V.; BACCARELlI A. Environmental Epigenetics. Heredity. 105(1): 105-112, 2010.

BONETTA, L. Epigenomics: Detailed analysis. Nature. 454: 795-798, 2008.

BRASIL. MINISTÉRIO DO TRABALHO E EMPREGO. Portaria ${ }^{\circ} 3.214$ de 08 de junho de 1978. Norma Reguladora 7 (NR-7): Programa de Controle Médico em Saúde Ocupacional. Modificada pela Portaria SSST n. ${ }^{\circ}$ 24, de 29 de dezembro de 1994. 
BRASIL. MINISTÉRIO DO TRABALHO E EMPREGO. Portaria n $^{\circ} 3.214$ de 08 de junho de 1978. Norma Reguladora 15 (NR-15): Atividades e Operações Insalubres.

BRITTO, A. et al. Epigenetic Modifications Due to Heavy Metals Exposure in Children Living in Polluted Areas. Current Genomics, 15, 464-468, 2014.

BROBERG, K., ENGSTRÖM K., AMEER, S. Gene-Environmental Interactions for metals. Handbook on the Toxicology of Metals. Academic Press. Cap 12, pg 239-241, 2014.

BRONNER, F. Bone and calcium homeostasis. Neurotoxicology. 13: 775-782, 1992.

BURKITT, H. G., Young, B., Heath, J. W. Wheater's functional histology: a text and colour atlas. 3rd ed. Edinburgh: Churchill Livingston, 1993.

BURTIS, C. A., ASHWOOD, E. R. Clinical Chemistry. Philadelphia: Saunders, 1999.

CENTERS FOR DISEASE CONTROL AND PREVENTION (CDC). Blood lead levelsUnites States 1999 to 2002. 54:513-516, 2005.

CHANDA S. et al. DNA hypermethylation of promoter of gene p53 and p16 in arsenicexposed people with and without malignancy. Toxicological Siences. 89: 431-437, 2006.

CHENG, T. F., CHOUDHURI, S., MULDOON-JACOBS, K. Epigenetic targets of some toxicologically relevant metals: a review of the literature. Journal of Applied Toxicology 32: 643-53, 2012.

COHEN, J. A, KAPLAN, M. M. The SGOT/SGPT ratio - an indicator of alcoholic liver disease. Digestive Diseases and Sciences. 24: 835-8, 1979.

COPPIN J. F. et al. Interplay between cellular methyl metabolism and adaptive efflux during oncogenic transformation from chronic arsenic exposure in human cells. Journal of Biological Chemistry. 283(28), 19342-50, 2008.

CORDEIRO, R. O saturnisno em Bauru. Saúde do trabalhador. São Paulo: 47-83, 1988.

CORDEIRO, R., LIMA-FILHO, E. C. A inadequação dos valores dos limites de tolerância biológica para a prevenção da intoxicação profissional pelo chumbo no Brasil. Cadernos de Saúde Pública. 11: 177-186, 1995.

DE CAPITANI, E. M. et al. Fontes de exposição humana a chumbo no Brasil. Medicina. 42: 311- 318, 2009.

DEJEUX, E.; AUDARD, V.; CAVARD, C. et al. Rapid identification of promoter hypermethylation in hepatocellular carcinoma by pyrosequencing of etiologically homogeneous sample pools. The Journal of Molecular Diagnostics. 9:510-520, 2007. 
DOBRAKOWSKI, M. et al. Association between subchronic and chronic lead exposure and levels of antioxidants and chemokines. International Archives of Occupational and Environmental Health. Oct; 89(7): 1077-85, 2016.

DUFOUR, D. R. et al. Diagnosis and monitoring of hepatic injury. I. Performance characteristics of laboratory tests. Clinical Chemistry. 46: 2027-49, 2000.

DUYDU, Y. et al. Correlation between lead exposure indicators and sister chromatid exchange (sce) frequencies in lymphocytes from inorganic lead exposed workers. Archives of Environmental Contamination and Toxicology. 41: 241-246, 2001.

EATON, D. L.; HAMEL, D. M. Increase in $\gamma$-glutamylcysteine synthetase activity as a mechanism for butylated hydroxyanisole-mediated elevation of hepatic glutathione. Toxicology and Applied Pharmacology. 126:145-149, 1994.

EID, A. ET al. Developmental lead exposure and lifespan alterations in epigenetic regulators and their correspondence to biomarkers of Alzheimer's disease. Alzheimer's \& Dementia: Diagnosis, Assessment \& Disease Monitoring. (2): 123-131, 2016.

ENGSTRÖM K. S. et al. Genetic variation in glutathione-related genes and body burden of methylmercury. Environmental Health Perspectives. 116: 734-739, 2008.

FARANT, J. P., WIGFIELD, D. C. Biomonitoring lead exposure with delta-aminolevulinate dehydratase (ALA-D) activity ratios. International Archives of Occupational and Environmental Health. 51: 15-24, 1982.

FAULK. C., DOLINOY, D. C. Timing is everything: the when and how of environmentally induced changes in the epigenome of animals. Epigenetics. 6: 791-7, 2011.

FEINBERG, A. P. et al. The epigenetic progenitor origin of human cancer. Nature Reviews Genetics. 7, 21-33, 2006.

FERNANDES, K. C. ET al. Polymorphism of Metallothionein 2A Modifies Lead Body Burden in Workers Chronically Exposed to the Metal. Public Health Genomics. 19:47-52, 2016.

FINGERMAN, I. M. et. al. NCBI Epigenomics: what's new for 2013. Nucleic Acids Research. 41: D221-D225, 2013.

FLORA, G. ET AL. Toxicity of lead: a review with recent updates. Interdisciplinary Toxicology. 5(2): 47-58, 2012.

FLORA, S. J. S. et al. Environmental occurrence, health effects and management of lead poisoning. In: José SC, José S, eds. Lead. Amsterdam, Elsevier Science: 158-228, 2006.

FRAGOU, D. ET. al. Epigenetic mechanisms in metal toxicity. Toxicology Mechanisms and Methods. 21(4): 343-352, 2011.

FRANKLIN, C. C. et al. Structure, function, and post-translational regulation of the catalytic and modifier subunits of glutamate cysteine ligase. Molecular Aspects of Medicine. 30: 8698, 2009. 
FRANKLIN, C. C. et al. Structure, function, and post-translational regulation of the catalytic and modifier subunits of glutamate cysteine ligase. Molecular Aspects of Medicine. 30(1-2): 86-98, 2009.

GARCÍA-LESTÓN, J. et al. Assessment of immunotoxicity parameters in individuals occupationally exposed to lead. Journal of Toxicology and Environmental Health A. 75(13-15):807-18, 2012.

GARÇON, G. et al. Biomonitoring of the adverse effects induced by the chronic exposure to lead and cadmium on kidney function: usefulness of alpha-glutathione S-transferase. The Science of the Total Environment. Mar, 377(2-3):165-172, 2007.

GHANWAT, G. H. et al. Biochemical effects of lead exposure on oxidative stress and antioxidant status of battery manufacturing workers of Western Maharashtra, India. Journal of Basic and Clinical Physiology and Pharmacology. 27(2): 141-6, 2016.

GIANNINI, E. et al. Increased levels of gammaGT suggest the presence of bile duct lesions in patients with chronic hepatitis C: absence of influence of HCV genotype, HCV-RNA serum levels, and HGV infection on this histological damage. Digestive Diseases and Sciences. 46: 524-9, 2001.

GIANNINI, E. G, TESTA, R., SAVARINO, V. Liver enzyme alteration: a guide for clinicians. Canadian Medical Association Journal. 172: 367-379, 2005.

GLAHN, F. et al. Cadmium, cobalt and lead cause stress response, cell cycle deregulation and increased steroid as well as xenobiotic metabolism in primary normal human bronchial epithelial cells which is coordinated by at least nine transcription factors. Archieves of Toxicology. 82: 513-524, 2008.

GOMES, W. R. et al. Milk and dairy products intake is associated with low levels of lead $(\mathrm{Pb})$ in workers highly exposed to the metal. Biological Trace Elements Research.178: 29, 2016.

GOODRICH, J. M. et al. Mercury biomarkers and DNA methylation among Michigan dental professionals. Environmental and Molecular Mutagenesis. 54, 195-203, 2013.

GOYER, R. A, CLARKSON, T. W. Toxic effects of metals. In: Klaassen CD, editor. Casarett \& Doull's Toxicology: The Basic Science of Poisons. 6th ed. New York: McGraw Hill. 811-837, 2001.

GRIFFITH, O. W., MULCAHY, R. T. The enzymes of glutathione synthesis: $\gamma$ glutamylcysteine synthetase. Advances in Enzymology and Related Areas of Molecular Biology. 73: 209-267, 1999.

GULSON, B. L. et al. Mobilization of lead from human bone tissue during pregnancy and lactation - a summary of long-term research. Science of the Total Environmental. 303: 79$104,2003$.

GUNDACKER, C. et al. Genetic background of lead and mercury metabolism in a group of medical students in Austria. Environmental Research. 109: 786-796, 2010. 
GUNDACKER, C. et al. The relevance of the individual genetic background for the toxicokinetics of two significant neurodevelopmental toxicants: mercury and lead. Mutation Research. 705: 130-140, 2010.

GURER, H. et al. Correlation between clinical indicators of lead poisoning and oxidative stress parameters in controls and lead-exposed workers. Toxicology. 195: 147-154, 2004.

HALL, J. L. Cellular mechanisms for heavy metal detoxification and tolerance. Journal of Experimental Botany. Southampton, v. 53, n. 366, p. 1-11, Jan. 2002.

HALliWElL, B., GUTTERIDGE, J. M. C. Free Radical in Biology and Medicine. Clarendon Press. 86-123, 1989.

HANNA, C. W. et al. DNA methylation changes in whole blood is associated with exposure to the environmental contaminants, mercury, lead, cadmium and bisphenol A, in women undergoing ovarian stimulation for IVF. Human Reproduction. 27: 1401-10, 2012.

HOFFMAN, D. J. et al. Developmental toxicity of lead-contaminated sediment to mallard ducklings. Archives of Environmental Contamination and Toxicology. 39: 221-32, 2000.

HOU, L. et al. Environmental chemical exposures and human epigenetics. International Journal of Epidemiology. 1-27, 2011.

HUNAITI, A. et al. Lead concentration and the level of glutathione S-transferase, reductase and peroxidase in the blood of some occupational workers from Irbid City, Jordan. Science of the Total Environmental. 170: 95-100, 1995.

HUR, K. et al. Hypomethylation of long interspersed nuclear element-1 (LINE-1) leads to activation of proto-oncogenes in human colorectal cancer metastasis. Gut. Apr; 63(4):635-46, 2014.

HUSE, S. M. et al. Accuracy and quality of massively parallel DNA pyrosequencing. Genome Biology. 8(7): 143, 2007.

INTERNATIONAL AGENCY FOR RESEARCH ON CANCER (IARC). Monographs on the Evaluation of Carcinogenic Risks to Humans. Lyon, France, IARC Press. Vol. 87, 2006.

JOMOVA, K., VALKO, M. Advances in metal-induced oxidative stress and human disease. Toxicology. 283: 65-87, 2011.

KAYAALTI Z. et al. The potential effect of metallothionein $2 \mathrm{~A}-5 \mathrm{~A} / \mathrm{G}$ single nucleotide polymorphism on blood cadmium, lead, zinc and copper levels. Toxicology and Applied Pharmacology. 256;1-7, 2011.

KELADA, S. N. et. al. Aminolevulinic acid dehydratase genotype and lead toxicity: A HuGE review. American Journal of Epidemiology. 154: 1-13, 2001.

KHAN, D. A. et. al. Lead-induced oxidative stress adversely affects health of the occupational workers. Toxicology and Industry Health. 24(9):611-8, 2008.

KHANSAKORN, N. et al. Genetic Variations of Glutathione S-Transferase Influence on Blood Cadmium Concentration. Journal of Toxicology. 35:6 1-26, 2012. 
KIM, J. et al. Environmental Exposure to Lead $(\mathrm{Pb})$ and Variations in Its Susceptibility. Journal of Environmental Science and Health. 32:2, 159-185, 2014.

KIM, K. R.; LEE, S. W.; PAIK, N. W. 1. Cross-sectional analysis of blood lead level of entire Korean lead workers. Industrial Health. Apr;44(2):318-27, 2006.

KRZESLAK, A. et al. Effect of metallothionein 2A gene polymorphism on allele-specific gene expression and metal content in prostate cancer. Toxicology and Applied Pharmacology. 268(3): 278-285. 2013.

KURDYUKOV, S., BULLOCK, M. DNA Methylation Analysis: Choosing the Right Method. Biology. 5: 1-3, 2016.

LANG, F. et al. Ceramide in suicidal death of erythrocytes. Cellular Physiology and Biochemistry. 26: 21-28, 2010.

LANGSTON, J. W.; CIRCU, M. L.; AW, T.Y. Insulin stimulation of $\gamma$-glutamylcysteine ligase catalytic subunit expression increases endothelial GSH during oxidative stress: Influence of low glucose. Free Radical Biology and Medicine. 45: 1591-1599, 2008.

LEE, J. I.; KANG, J.; STIPANUK, M. H. Differential regulation of glutamate-cysteine ligase subunit expression and increased holoenzyme formation in response to cysteine deprivation. Biochemical Journal. 393(1): 181-190, 2006.

LI, C. et al. Epigenetic marker (LINE-1 promoter) methylation level was associated with occupational lead exposure. Clinical Toxicology. 1-5, 2013.

LI, C. et al. Lead exposure suppressed $A L A D$ transcription by increasing methylation level of the promoter CpG islands. Toxicology Letters. 30: 48-53, 2011.

LI, Y. et al. Lead Exposure during Early Human Development and DNA Methylation of Imprinted Gene Regulatory Elements in Adulthood. Environmental Health Perspectives. 124:666-673, 2016.

LI, Z. et al. High-resolution melting analysis of ADAMTS18 methylation levels in gastric, colorectal and pancreatic cancers. Medical Oncology. Northwood, v. 27, p. 998-1004, 2010.

LIEB, J. D. Applying whole-genome studies of epigenetic regulation to study human disease. Cytogenetic and Genome Research. 114(1): 1-15, 2006.

LIU, J. et al. n. In: Klassen, C.D. Casarett and Doull's Toxicology: The Basic Science of Poisons. McGraw-Hill: 1309, 2010.

LIU, R. M. et al. Regulation of [Ah] gene battery enzymes and glutathione levels by 5,10dihyroindeno[1,2-b]indole in mouse hepatoma cell lines. Carcinogenesis. 15: 2347-2352, 1994.

LOPES, H. J. J. Enzimas no laboratório clínico: aplicações diagnósticas. Analisa diagnóstica. Belo Horizonte: 1998.

LOPES, H. J. J. O laboratório clínico na avaliação da função renal. Analisa diagnóstica. Belo Horizonte: 2004. 
LUO, M. et al. Epigenetic histone modification regulates developmental lead exposure induced hyperactivity in rats. Toxicology Letters 225: 78-85, 2014.

MAK VALUE DOCUMENTATION. Lead and its inorganic compounds (inhalable fraction). The MAK Collection for Occupational Health and Safety. 166-192, 2012.

MANTON, W. I. et al. Release of lead from bone in pregnancy and lactation. Environmental Research. 92: 139-151, 2003.

MARTINEZ-ZAMUDIO, R., HA, H. C. Environmental epigenetics in metal exposure. Epigenetics. 6:7, 820-827; 2011.

MELO E MATTOS, S.V. et al. Evaluation of exposure to lead inorganic compounds in workers of metroplotitan Belo Horizonte - 1998 to 1993. Revista Brasileira de Saúde Ocupacional. 22: 7-16, 1994.

MENEGotTo, R. M., PAOLIELlO, M. M. B. Exposição Ocupacional ao Chumbo e Influência nos Índices Hematológicos. Revista Brasileira de Toxicologia. 14: 31-34, 2001.

METHHC: A database of DNA Methylation and gene expression in Human Cancer. Disponível em: <http://methhc.mbc.nctu.edu.tw/php/index.php>. Acesso em: 22 de outubro de 2017.

MINISTÉRIO DA SAÚDE. Contaminantes químicos: Chumbo. 2015. http://portalsaude.saude.gov.br/index.php/o-ministerio/principal/leia-mais-o-ministerio/1117secretaria-svs/vigilancia-de-a-a-z/contaminantes-quimicos/contaminantes-quimicoslinha1/16195-chumbo. Acesso em: 30 Ago 2017.

MINOZZO R. et al. Prevalência de anemia em trabalhadores expostos ocupacionalmente ao chumbo. Revista Brasileira de Hematologia e Hemoterapia. 31(2): 94-97, 2009.

MOREIRA, F. R., MOREIRA, J. C. A. Cinética do chumbo no organismo humano e sua importância para a saúde. Ciência e Saúde Coletiva 1: 167-181, 2004.

MULCAHY, R. T.; BAILEY, H. H.; GIPP, J. J. Up-regulation of $\gamma$-glutamylcysteine synthetase activity in melphalan-resistant human multiple myeloma cells expressing increased glutathione levels. Cancer Chemother Pharmacology. 34: 67-71, 1994.

MUTHUSAMY, V. et al. Redefining regulation of DNA methylation by RNA interference. Genomics. 96(4): 191-198, 2010.

NEUROHR, C. et al. Glutamate-cysteine ligase modulatory subunit in BAL alveolar macrophages of healthy smokers. European Respiratory Journal. 22(1): 82-87, 2003.

NICIURA, S. C. M., SARAIVA, N. Z. Livro: EPIGENÉTICA: Bases moleculares, efeitos na fisiologia e na patologia, e implicações para a produção animal e a vegetal. Embrapa. Brasília, 2015.

NIOSH. The National Institute for Occupational Safety and Health. Chemical Listing and Documentation of Revised IDLH Values (as of 3/1/95).

NTP. National Toxicology Program: NTP Monograph on health effects of low-level lead. Junho de 2012. 
NYE, M. D., HOYO, C., Murphy, S. K. In vitro lead exposure changes DNA methylation and expression of IGF2 and PEG1/MEST. Toxicology in Vitro. 544-550, 2015.

O'FLAHERTY, E. J. Physiologically based models of metal kinetics. Critical Reviews in Toxicology. 28: 271- 317, 1998.

OGINO, S. et al. A cohort study of tumoral LINE-1 hypomethylation and prognosis in colon cancer. Journal of the National Cancer Institute. Dec 3; 100(23):1734-8, 2008.

OSHA. Occupational Safety and Health Administration. Lead: Toxic and Hazardous Substances. Occupational Safety and Health Standards. 1910.1025.

PAOLIELLO, M. B., DE CAPITANI, E. M. Environmental Contamination and Human Exposure to Lead in Brazil. Reviews of Environmental Contamination and Toxicology. 184:59-96, 2007.

PAOLIELlO, M. M. B., DE CAPITANI, E. M. Chumbo. In: Metais: Gerenciamento da toxicidade. São Paulo, Atheneu. 353-398, 2003.

PATRICK, L. Lead toxicity part II: the role of free radical damage and the use of antioxidants in the pathology and treatment of lead toxicity. Alternative Medicine Review. 11: 114-127, 2006.

PEARCE, J. M. Burton's line in lead poisoning. European Neurology. 57: 118-119, 2007.

PILSNER, J. R. et. al. Influence of Prenatal Lead Exposure on Genomic Methylation of Cord Blood DNA. Environmental Health Perspectives. 117(9): 1466-1471, 2009.

POUNDS, J. G. et al. Cellular and molecular toxicity of lead in bone. Environmental Health Perspectives. 91: 17-32, 1991.

QUILLIEN, V.; LAVENU, A.; DUCRAY, F. et al. Validation of the high-performance of pyrosequencing for clinical MGMT testing on a cohort of glioblastoma patients from a prospective dedicated multicentric trial. Oncotarget. 7:61916-61929, 2016.

RABINOWITZ, M. B. et al. Dentine lead and child intelligence in Taiwan. Archives of Environmental \& Occupational Health. 46: 351-360 1991.

RAHMAN, I., MACNEE, W. Oxidative stress and regulation of glutathione in lung inflammation. European Respiratory Journal. 534-554, 2000.

RAUDENSKA, M. et al. Metallothionein polymorphisms in pathological processes. The Metallomics. 6: 55-68, 2014.

REICHARD, J. F. et al. Long term low-dose arsenic exposure induces loss of DNA methylation. Biochemical and Biophysical Research Communications. 352: 188-192, 2007.

REJ R. Aminotransferases in disease. Clinics in Laboratory Medicine. 9: 667-87, 1989.

RICHARD, S. A., PHILliPS, J. D., KUSHNER, J. P. Biosynthesis of heme in mammals. Biochimica et Biophysica Acta. 1763: 723-736, 2006. 
ROSALKI, S.B., TARLOW, D., RAU, D. Plasma gamma-glutamyl transpeptidase elevation in patients receiving enzyme-inducing drugs. The Lancet. 2: 376-7, 1971.

SANCHEZ, O. F. et al. Lead $(\mathrm{Pb})$ exposure reduces global DNA methylation level by noncompetitive inhibition and alteration of dnmt expression. Metallomics 229: 149-160, 2017.

SANDERS A. P. et al. Cadmium exposure and the epigenome: exposure-associated patterns of DNA methylation in leukocytes from mother-baby pairs. Epigenetics. 9: 212-221, 2014.

SARYAN, L. A., ZENZ,C. Lead and its compounds. In: Zenz O.C. et al. (Eds). Occupational Medicine. 506-541, 1994.

SEN, A. et al. Early life lead exposure causes gender-specific changes in the DNA methylation profile of DNA extracted from dried blood spots. Epigenomics. 7: 379-393, 2015a.

SEN, A. et al. Lead exposure induces changes in 5-hydroxymethylcytosine clusters in CpG islands in human embryonic stem cells and umbilical cord blood. Epigenetics. 10: 607-621; $2015 b$.

SEVERSON, P. L. et al. Agglomerates of aberrant DNA methylation are associated with toxicant- induced malignant transformation. Epigenetics. 7: 1238-1248, 2012.

SHEN, J. C. et al. The rate of hydrolytic deamination of 5-methylcytosine in doublestranded DNA. Nucleic Acids Research. 22:6, 1994.

SILBERGELD EK, SCHWARTZ J, MAHAFFEY K. Lead and osteoporosis: mobilization of lead from bone in postmenopausal women. Environmental Research. 47(1):79-94, 1988.

SILVA, F. V. Avaliação da influência do polimorfismo Pro ${ }^{198}$ Leu da glutationa peroxidase sobre o estresse oxidativo em população exposta ao chumbo. 2008, 54 pgs, Mestrado. Ribeirão Preto: Universidade de São Paulo, 2008.

SODRE, F. L., COSTA, J. C. B., LIMA, J. C. C. Avaliação da função e da lesão renal: um desafio laboratorial. Jornal Brasileiro de Patologia e Medicina Laboratorial. 43: 5, 2007.

STRENGTHENING THE REPORTING OF GENETIC ASSOCIATION STUDIES (STREGA): an extension of the STROBE statement. European Journal of Epidemiology. 24(1): 37-55, 2009.

STRENGTHENING THE REPORTING OF OBSERVATIONAL STUDIES IN EPIDEMIOLOGY (STROBE): explanation and elaboration, e297; E. Von Elm et al. The Strengthening the Reporting of Observational Studies in Epidemiology (STROBE) statement: guidelines for reporting observational studies, PLoS Med. 4, 2007.

SUGAWARA, E. et al. Lipid peroxidation and concentration of glutathione in erythrocytes from workers exposed to lead. British Journal of Industrial Medicine. 48: 239-42, 1991.

THE BLUEPRINT CONSORTIUM. Quantitative comparison of DNA methylation assays for biomarker development and clinical applications. Nature Biotechnology. 34:726-737, 2016.

TOST, J. DNA Methylation: An Introduction to the Biology and the Disease-Associated Changes of a Promising Biomarker. Molecular Biotechnology. 44:71, 2010. 
TOST, J. Livro: Epigenetics. The Dynamic Epigenome: The impact of the environmental on epigenetic regulation of gene expression and developmental programming. Horizon Scientific Press. United Kingdom, 343-348, 2008.

TOST, J., Gut, I. Prtocol: DNA methylation analysis by pyrosequencing. Nature Publishing Group. Published online on 6 September 2007.

TOST, J.; DUNKER, J.; GUT, I. G. Analysis and quantification of multiple methylation variable positions in $\mathrm{CpG}$ islands by pyrosequencing. BioTechniques. 35:152-156, 2003.

TSAIH, S. W. et al. Influence of Bone Resorption on the Mobilization of Lead from Bone among Middle-Aged and Elderly Men: The Normative Aging Study. Environmental Health Perspectives. 109(10): 995-999, 2001.

VAHTER, M. et al. Gender differences in the disposition and toxicity of metals. Environmental Research. 104: 85-95, 2007

VALKO, M. et al. Metals, toxicity and oxidative stress. Current Medicinal Chemistry. 12: 1161-1208, 2005.

VANDERLINDE, R. E. Review of pyridoxal phosphate and the transaminases in liver disease. Annals of Clinical \& Laboratory Science. 16: 79-93, 1986.

WHITFIELD, J. B. et al. Evidence of genetic effects on blood lead concentration. Environmental Health Perspectives. 115: 1224-1230, 2007.

WHITFIELD, J. B. et al. Genetic effects on toxic and essential elements in humans: arsenic, cadmium, copper, lead, mercury, selenium, and zinc in erythrocytes. Environmental Health Perspectives. 118: 776-782, 2010.

WOJDACZ, T. K., DOBROVIC, A., HANSEN, L. L. Methylation-sensitive high-resolution melting. Nature Protocols. London, v. 3, p. 1903-1908, 2008.

WOLFORD, J. K.; YEATTS, K. A. Pyrosequencing. In: Molecular Diagnostics. Elsevier. 127-130, 2005.

WRIGHT, R. O. et al. Biomarkers of lead exposure and DNA methylation within retrotransposons. Environmental Health Perspectives. 118: 790-795, 2010.

XIONG, Z., LAIRD, P. W. COBRA: a sensitive and quantitative DNA methylation assay. Nucleic Acids Research. 25: 2532-2534, 1997.

XU, L. H. et al. Lead Induces Apoptosis and Histone Hyperacetylation in Rat Cardiovascular Tissues. PLoS One. 10: 0129091, 2015.

YAMANE, Y. et al. Expression of multidrug resistance protein/GS-X pump and $\gamma-$ glutamylcysteine synthetase genes is regulated by oxidative stress. Journal of Biological Chemistry. 273: 31075-31085, 1998.

YANG, Y. et al. Interaction between the catalytic and modifier subunits of glutamate-cysteine ligase. Biochemical Pharmacology. 74: 372-381, 2007. 
ZHU, C. et al. Hypomethylation of long interspersed nuclear element-1 (LINE-1) is associated with poor prognosis via activation of c-MET in hepatocellular carcinoma. Annals of Surgical Oncology. 4: 729-35, 2014.

ZHU, H. et al. Race/Ethnicity-Specific Association of Vitamin D and Global DNA Methylation: Cross-Sectional and Interventional Findings. PLoS ONE. 11: e0152849, 2016. 